\title{
Техника «LOZENGE» при одноэтапной реконструкции молочной железы
}

\author{
Г. Е. Самойленко, С. О. Жариков, Р. П. Климанский \\ Донецкий национальный медицинский университет, г. Лиман
}

\section{«LZENGE» procedure of a one-staged reconstruction of a mammary gland}

\author{
G. E. Samoylenko, S. O. Zharikov, R. P. Klimanskyi \\ Donetsk National Medical University, Liman
}

Ежегодно в мире регистрируют более миллиона наблюдений рака молочной железы (РМЖ), из них более 16 тысяч - в Украине. РМЖ занимает первое место в структуре онкопатологии и, как ни одно другое онкологическое заболевание, затрагивает профессиональную, социальную и интимную стороны жизни женщины $[1,2]$. В лечении РМЖ стандартным считается радикальное хирургическое вмешательство, которое, наряду с физической, связано и со значительной психологической травмой. Вопрос о сохранении кожи во время реконструкции для сохранения формы молочной железы остается спорным с начала ХХ века [3, 4].

В последние десятилетия техника радикальной мастэктомии представлена все более щадящими операциями типа Пейти и Маддена. С точки зрения пластических хирургов, большое практическое значение имеет сохранение при возможности кожных покровов, сосково-ареолярного комплекса (САК) и инфрамаммарной складки (ИС), что принципиально для достижения удовлетворяющего женщину эстетического результата реконструктивной операции [5].

Восстановление молочной железы одномоментно с мастэктомией имеет несомненный практический интерес и является существенным моментом в реабилитации больных с РМЖ. Введение сразу силиконового имплантата в пространство под грудной мышцей позволяет увеличить степень проекции реконструируемой молочной железы, он может быть использован для реконструкции молочной железы небольшого размера с минимальным птозом [6].

Цель исследования: улучшить эстетические результаты одномоментной реконструкции молочной железы при РМЖ и маммоптозе за счет усовершенствованного метода «Lozenge».

Нами выполнена одномоментная реконструкция молочной железы после мастэктомии силиконовым эндомаммопротезом с использованием техники «Lozenge». Также успешно мы использовали технику «Lozenge» при реконструкции молочной железы у больной с РМЖ на фоне маммоптоза.

Приводим наблюдения.

Больная К., 56 лет (и. б. № 2087), госпитализирована с диагнозом «рак левой молочной железы T2N1M0». Размер молочной железы - 3-й, маммоптоз 2-й степени, ассиметрия. Опухоль локализуется в верхне-наружном квадранте левой молочной железы. Пальпаторно определяется опухолевидное образование с нечеткими контурами, неровной поверхностью, округлой формы, плотной консистенции, размерами 2 × 2 см, аксиллярный лимфатический узел слева размерами $1 \times 1$ см.

Больная обследована. Данных об отдаленных метастазах не выявлено. Маммография: в верхне-наружном квадранте левой молочной железы опухоль с нечеткими контурами, неоднородная по структуре, с наличием микрокальцинатов размерами $2 \times 2$ см.

Гистологическое и иммуногистохимичекое исследование опухоли после трепан-биопсии: высокодифференцированный железистый инфильтрирующий дольковый рак, уровень рецепторов эстрогенов - 8 баллов, уровень рецепторов прогестерона - 8 баллов, сверхэкспрессия Her2/neu - негативная.

Диагноз: рак молочной железы Т2N1M0; маммопто3 2-й степени по P. Regnault. Гистологическое заключение после операции: инфильтрирующий дольковый высокодифференцированный рак, железистый вариант строения.

Больной выполнена операция: мастэктомия левой молочной железы с подключично-подмышечно-подлопаточной лимфаденэктомией и одномоментной реконструкцией эндомаммопротезом «Allergan» 410 FF 255.

В плановом режиме проведено 4 цикла полихимиотерапии по схеме FAC и дистанционную лучевую терапию в режиме стандартного фракционирования на медицинских ускорителях с энергией 6 МэВ, разовая очаговая доза 1,8 - 2,0 Гр, 5 фракций в неделю, суммарная очаговая доза 50 Гр.

В настоящее время больная получает гормонотерапию и находится под наблюдением онколога. При осмотре через 12 мес у больной отмечены отличные эстетические результаты лечения.

Способы одномоментной подкожной мастэктомии в целом обеспечивают удовлетворительный косметический эффект. Однако они, независимо от того, используют силиконовые имплантаты или аутологичные тканевые комплексы, имеют один недостаток - реконструкция не всегда соответствует желаемым форме и объему 
молочной железы. Наилучший косметический результат реконструкции молочной железы удается достичь при размещении имплантата только под грудную мышцу, вне его непосредственного контакта с подкожным слоем во избежание нарушения кровоснабжения вследствие натяжения эндопротезом тканей лоскутов кожи нижнего полюса органа [7].

Оригинальная методика формирования нижней ножки (англ. «Lozenge» - ромб, пирамида) впервые была представлена на Конгрессе Бразильского общества пластической хирургии в 1971 г., а эффективность ее обобщена многолетним опытом Л. Рибейро [8].

Нами успешно использована методика «Lozenge» именно при реконструкции у больной с РМЖ на фоне маммоптоза. Мы модифицировали технику J.Bostwick, который, применяя разметку по Wise, выполнял профилактическую мастэктомию с одномоментной реконструкцией, используя деэпителизированный кожный лоскут для укрытия имплантата [9, 10].

При планировании вмешательства крайне важно определить желаемую форму в соответствии с исходной проекцией и размерами «пятна» молочной железы, степенью птоза контрлатеральной молочной железы и возможностью ее мастопексии. Планируя операцию, учитываем стадию заболевания, биологические и иммуногистохимические характеристики опухоли, ее расположение, размер и форму контрлатеральной молочной железы, конституциональный тип женщины, объем и состояние местных тканей, планируемую лучевую терапию. Считаем неприемлемым откладывать либо менять план адъювантного лечения в пользу эстетического результата выполняемой пластической операции.

Техника радикальной мастэктомии с использованием лоскута на нижней ножке. Кожно-жировой лоскут формируем в нижнем полюсе молочной железы. Нижняя ножка получает достаточное и надежное кровоснабжение от четвертых, пятых и шестых межреберных сосудов-перфорантов внутренних грудных артерий. Венозный и лимфатический дренаж осуществляется через внутреннюю грудную вену и лимфатические узлы в направлении, противоположном артериальному току. Деэпителизированная кожа помогает выдерживать натяжение и может быть фиксирована к грудной фасции.

В полусидячем положении пациента маркируем планируемые границы ареолы диаметром 4 см. По среднеключичной линии выше ареолы отмечаем точку А, которая соответствует проекции ИС на верхнем полюсе железы. Посредством «щипкового» сведения кожи пальцами определяем и отмечаем точки В и С, которые соединяем с субмаммарной складкой дугообразными линиями. Приподнимая грудь так, чтобы был виден нижний полюс, выполняем рисунок нижней ножки в центральной части с расширением книзу на расстоянии $1-2$ см ниже кромки ареолы.

По контуру рисунка выполняем деэпителизацию ножки, по границе которой рассекаем ткани в глубину до мышцы и формируем кожно-жировой лоскут желательно не менее 2 см толщиной, который кровоснабжается сетью из перфорантных сосудов. Подкожно во всех направ- лениях иссекаем ткани молочной железы в одном блоке с клетчаткой подлопаточной, подмышечной, подключичной групп с оставлением САК. Операционного доступа при таком раскрое достаточно, чтобы избежать дополнительных разрезов в подмышечной области.

Возможность возникновения кровотечения в раннем послеоперационном периоде заслуживает особого внимания. Это объясняется особенностью архитектоники сосудов, а также наличием большого числа перфорантов. Мы в обязательном порядке придерживаемся бережной диссекции по ходу сосудов с максимальным сохранением их интактности по ходу удаления клетчаточных депо в аксиллярно-подключичной зоне. Основной причиной образования послеоперационных сером считаем именно наличие полости в аксиллярной зоне при сохранности грудных мышц. Выполняем частичную ее тампонаду путем миопластики малой грудной мышцей после отсечения сухожилия от клювовидного отростка лопатки и подшиванием кожных лоскутов в аксиллярной области к грудной фасции. После удаления препарата пересекаем волокна большой грудной мышцы в виде буквы «Т» по В. Д. Пинчук.

Под большой грудной мышцей формируем ложе для эндопротеза. Верхний и наружный края охватываем и укрепляем узловыми швами между большой и культей малой грудных мышц с таким расчетом, чтобы верхний край имплантата и его боковые контуры были покрыты мышечной тканью. При соблюдении этого приема контурирование эндопротеза в верхнем склоне сводится до минимума. Нижний контур протеза располагаем на уровне созданной субмаммарной складки под сформированным кожно-жировым лоскутом нижнего полюса молочной железы. Свободный край рассеченной большой грудной мышцы сшиваем непрерывным швом с деэпителизированным кожно-подкожным лоскутом.

САК перемещаем в новое положение и фиксируем нерассасывающимися «U»-швами Gillies-Perseu. Точки В и С соединяются посредине основы нижней ножки, и направление непрерывного или узлового кожного шва принимает форму либо в виде перевернутой буквы «Т», либо буквы «L».

Дренированию подлежат две полости: ложа имплантата и подкожной диссекции железы, подмышечной и подключичной областей. Активные дренажи выводим через контрапертуры, расположенные в подмышечной ямке и к ложу имплантата. Подобные меры позволяют на 98\% уменьшить объем лимфореи. Срок функционирования дренажей - 10 и 7 дней соответственно.

Одномоментная реконструкция - это всегда компромисс между радикальностью и эстетическим результатом операции. Реконструкция груди с помощью имплантатов имеет ограничения. Наряду с достаточно высоким риском развития капсульной контрактуры могут возникать проблемы с заживлением раны, связанные с натяжением истонченных кожных покровов, особенно если объем имплантата превышает 400 - 600 мл.

Одним из неблагоприятных моментов для эндопротезирования считается необходимость проведения сеансов лучевой терапии. Адъювантная лучевая терапия мо- 
жет приводить к липо- и дермонекрозу с последующей экструзией имплантата. После облучения груди на фоне әритемы зачастую развивается отек с трансформацией в фиброз и потерей эластичности тканей. Но основной причиной для отказа от проведения интраоперационной радиотерапии (ELIOT) в пользу адъювантной лучевой терапии считаем плохую васкуляризацию САК.

Даже после эффективных неосложненных реконструкций у небольшого числа пациенток возникает неудовлетворенность эстетическим результатом. При этом сохраняется возможность не только воссоздать орган, но и корректировать контрлатеральный почти симметрично. Дополнительная коррекция может включать мастопексию контрлатеральной молочной железы, липофиллинг восстановленной или здоровой железы, формирование соска, татуаж ареолы (при их отсутствии).

\section{Выводы}

При РМж операцией выбора, по нашему мнению, является сохраняющая кожу мастэктомия с одномоментной реконструкцией силиконовым эндопротезом. Данная методика, как и другие хирургические вмешательства, не лишена побочных эффектов, но их число не выходит за общепринятые рамки, а эстетико-функциональные показатели одни из самых высоких в реконструктивной хирургии молочной железы.

\section{References}

1. Chatterjee A. Long term effects of modern breast cancer surgery. Gland Surg. 2018 Aug;7(4):366-70. doi: 10.21037/gs.2017.10.09. Review.

2. Kijima Y, Shinden Y, Hirata M, Natsugoe S. Oncoplastic breast surgery and breast reconstruction. Nihon Geka Gakkai Zasshi. 2016 Nov;117(6):503-8. PMID: 30173474. [Japanese].

3. Delay E, Savu T, Atanasiu M. Lipomodeling in breast reconstruction. Ann Chir Plast Esthet. 2018 Aug 24. pii: S0294-1260(18)30098-0. doi: 10.1016/j.anplas.2018.06.012. [French].

4. Seth AK, Allen RJ Jr. Modern techniques and alternative flaps in microsurgical breast reconstruction. J Surg Oncol. 2018 Aug 21. doi: 10.1002/ jso.25198. [Epub ahead of print] Review.

5 Jain A, Vats M, Neogi S, Khwaja GA. Paraneoplastic cerebellar degeneration with bilateral facial palsy: a rare primary presentation of breast cancer. BMJ Case Rep. 2018 Jun 21;2018. pii: bcr-2018-224996. doi: 10.1136/bcr-2018-224996.

6. Chai L, Zhang X. Application of serratus anterior muscle flap combined with breast implants for breast reconstruction after modified radical mastectomy. Zhongguo Xiu Fu Chong Jian Wai Ke Za Zhi. 2017 Sep 1;31(9):1098-101. doi: 10.7507/1002-1892.201704032. Chinese.

7. Chen X, Xia F, Luo J, Ma J, Yang Z, Zhang L, et al. Postmastectomy radiotherapy reduces locoregional and disease recurrence in patients with stage II-III triple-negative breast cancer treated with neoadjuvant chemotherapy and mastectomy. Onco Targets Ther. 2018 Apr 5;11:197380. doi: $10.2147 /$ OTT.S158482.

8. Li G, Qin S, Sun X, Wang J, Zhang Y, Zhang J, et al. Retrospective observational cohort study on cosmetic outcome of using Ti-Ni memory alloy wire for intradermal suture following mastectomy in patients with breast cancer. Oncol Lett. 2018 Feb;15(2):2465-70. doi: 10.3892/ ol.2017.7603. Epub 2017 Dec 13.

9. Huang Y, Wu H, Luo Z. A retrospective study of optimal surgical management for occult breast carcinoma: Mastectomy or quadrantectomy? Medicine (Baltimore). 2017 Dec;96(52):e9490. doi: 10.1097/ MD.0000000000009490.

10. Sbitany H. Breast Reconstruction. Surg Clin North Am. 2018 Aug;98(4):845-57. doi: 10.1016/j.suc.2018.03.011. Epub 2018 May 28. Review.

Отримано 09.09.2018 